\title{
Impact of Torsional Resonance in Turbine-Generator Shaft Due to Multiple EAF Operation
}

\author{
Md. Minarul Islam ${ }^{1}$, Abdul Hasib Chowdhury ${ }^{2}$ \\ ${ }^{l}$ (Department of Electrical and Electronic Engineering, University of Dhaka, Bangladesh) \\ ${ }_{2}^{2}$ (Department of Electrical and Electronic Engineering, BUET, Bangladesh)
}

\begin{abstract}
Among the many nonlinear loads, electric arc furnace (EAF) is a potential source of sub-harmonic currents. Again, turbine-generator (T-G) shaft possesses natural frequencies in the sub-synchronous/subharmonic range. If those sub-harmonic frequencies match to natural frequencies there occur amplification of torsional oscillating torques transmitted among the masses of $T-G$ shaft. This may lead to damage rotating shaft, especially $T-G$ shaft, in the system. This paper assesses the severity of amplified oscillating torques on $T$ $G$ shaft due to multiple EAFs connected to same point of common coupling (PCC). This paper also assesses the impact due to relative location of EAFs from power stations. For this purpose, a lumped-mass model of T-G shaft and mathematical model of electric arc have been considered. EAFs have been connected to the same $P C C$ and their effects on T-G shaft have been measured with/without resonant excitation of torsional modes.
\end{abstract}

Keywords: EAF, Sub-synchronous frequencies, Electromagnetic torque, Torsional torque, PCC.

\section{Introduction}

A steam/gas T-G unit consists of many mass sections assembled in a shaft. At time of operation, there are oscillations/vibrations among the masses termed as torsional oscillations having subsynchronous frequencies(SSFs). Feeder of EAF acts as a current source of SSFs [1-8] which disturbs electromagnetic torque of synchronous machine. If there occurs torsional resonance (TR), the torsional oscillating torques (TOTs) will be amplified and cause stress on T-G shaft. The stress hinges on EAF actions and connection pattern to grid, characteristics of T-G and utility power system.

Fluctuation in real power at EAF was the source of SSF component of the electromagnetic torque which imposed significant resonant torque on turbine shaft and blades [5]. Smaller components-turbine blades, are dominantly affected by higher frequency components in electromagnetic torque whereas lower frequency components stimulate the TOTs in the main shaft sections [9]. Unbalanced currents engendered from EAF contribute to rotor heating of a small scale steam T-G [7-8]. The arm control of EAF and process of scraps melting enhance electrical dynamics which poses high threats to supply system [10]. In [8], it has been discussed that EAF affects the power quality due to its non-linear characteristic.

Remarkable oscillations of active power were noticed at two plants near a large steel mill which used EAF [11]. Amplification of TOTs can lead to fatigue in shaft, gear damage, retaining ring damage, severe damages to T-G shaft and eventually may lead to system blackouts [1]. The shaft can not guarantee long-term safety operation because of TR which is more harmful than three-phase fault [6]. TR caused failure of the first and second T-G shafts at the Mohave plant [14]. Shaft of a subsynchronous cascade drives was twisted and the coupling hub broke into two pieces due to TR [4].

A short study of torsional resonance due muliple EAF at same PCC is covered in [21]. However, a detailed study is necessay to understand how muliple number of EAF operating at same PCC affect rotating machine, more precisely T-G shaft, connected to the power system, more precisely . Furthermore, the study of the effect of relative position of the generator, PCC and EAF on T-G shaft system are of importance. This paper concentrates to assess the impact of simultaneous operation of multiple EAF on multi-stage T-G shaft: to quantify amplification of TOTs and find out its severity due to operation of multiple EAFs at the same PCC and at close proximity: to assess the effect of relative position of the generator, PCC and EAF on T-G shaft.

\section{Component Modeling}

The modeling of synchrnous generator, dynamic model of T-G rotor masses and EAF have been discussed in the following subsections.

\section{A. Electric Arc Furnace}

The load consuming behavior of EAF is very unpredictable which indicates difficulties in modeling EAF for simulation to predict probable risks that may be imposed on other electrical components and appliances connected to power grid. To understand certain already defined risks including harmonics, interharmonincs, SSFs and flicker, a precise mathematical model of three-phase EAF is very demanding. Furthermore, the 
external factors like the electrode arm control, melting stage of scrap materials should be considered in modeling EAF [15]. There are many EAF models which are primarily classified as time domain and frequency domain analysis model [16]. In time domain, there are different models described in [17-20]. Among them, dynamic model of electric arc has been considered for the simulation of EAF. This model was developed based on the principle of energy conservation, where relationships between supplied current to furnace electrode, $i_{\text {lead }}$, arc radius, $r_{\text {arc }}$, and arc voltage, $v_{\text {arc }}$, can be expressed by equations (1) and (2): where s (=1 or 2) represent size of the arc, $\mathrm{m}(=0$ to 2$)$ reflects the fact that the arc may be hotter in the interior if it has a larger radius , and $C_{1}$, $C_{2}, C_{3}$ are constants.

$$
\begin{gathered}
C_{1} r_{\text {arc }}^{s}+C_{2} r_{\text {arc }} \frac{d r_{\text {arc }}}{d t}=\frac{C_{3}}{r_{\text {arc }}^{m+2}} i_{\text {lead }}^{2} \\
v_{\text {arc }}=\frac{C_{3}}{r_{\text {arc }}^{m+2}} i_{\text {lead }}
\end{gathered}
$$

The simulated characteristic using above two equations is shown in Fig.

1 which explain how arc voltage changes with lead current. This is comparable to realistic EAF. This arc characteristic has a deterministic and a stochastic part, with the later becoming less and less significant as the process of meltdown progresses.

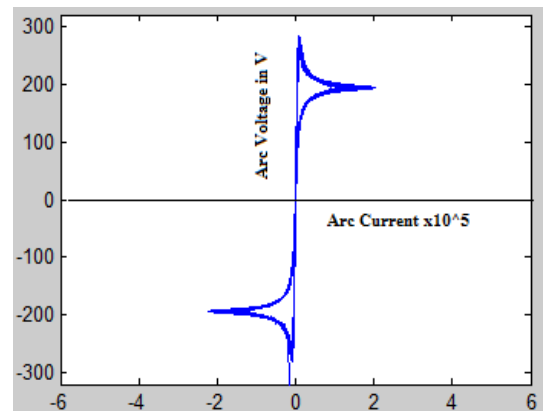

Fig. 1. Simulated characteristic of EAF

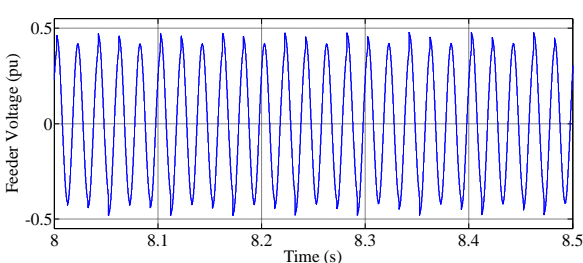

(a)

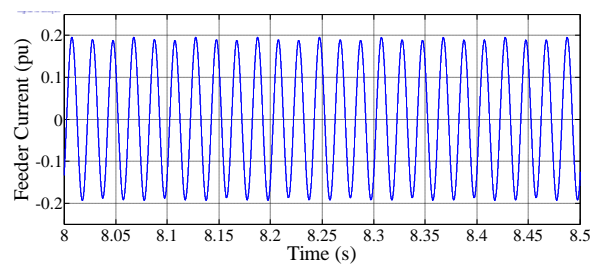

(b)

Fig. 2. Voltage and current at the primary side of furnace transformer (a) voltage waveform, (b) current waveform

The voltage and current waveforms in phase-a at primary of the furnace transformer are shown in Fig. 2. In EAF model, variation of arc resistance was considered $60 \%$. These waves are modulated that can be formulated by equations (3) and (4).

$$
\begin{gathered}
v_{a}(t)=\sqrt{2} V_{r m s}\left[1+\sum \Delta V_{h} \sin \left(2 \pi f_{h} t+\phi_{h}\right)\right] \sin \left(2 \pi f_{s} t\right) \\
i_{a}(t)=\sqrt{2} I_{r m s}\left[1+\sum I_{h} \sin \left(2 \pi f_{h} t+\phi_{h}\right)\right] \sin \left(2 \pi f_{s} t+\beta\right)
\end{gathered}
$$

The EAF feeder currents in phases- $b c$ can be represented by the equations (5) and (6).

$$
\begin{aligned}
& i_{b}(t)=\sqrt{2} I_{r m s}\left[1+\sum I_{h} \sin \left(2 \pi f_{h} t+\phi_{h}\right)\right] \sin \left(2 \pi f_{s} t+\beta-120^{0}\right) \\
& i_{c}(t)=\sqrt{2} I_{r m s}\left[1+\sum I_{h} \sin \left(2 \pi f_{h} t+\phi_{h}\right)\right] \sin \left(2 \pi f_{s} t+\beta-240^{\circ}\right)
\end{aligned}
$$
(

(1)




\section{B. Synchronous Generator}

Generator is the main interface between the T-G mechanical system and electrical power grid system. So, disturbances in the electrial system attact the generator first. The detailed modeling of the generator [14] is necessary to understand how it response to the disturbances. Disturbances attack T-G shaft through electromagnetic torque because it is the main linkage between the stator and rotor. Hence, characteristics of electromagnetic torque is vital here.

The electromagnetic torque depends not only on system current but also on other electrical parameters of the synchronous generator. For $\mathrm{n}^{\text {th }}$ generator, it can be expressed by equation (7) in dq0 reference fram.

$$
T_{e n}=\psi_{d n} i_{q n}-\psi_{q n} i_{d n}
$$

Where, dq0 current components:

$$
\begin{aligned}
& i_{d n}=\frac{2}{3}\left[i_{a n} \cos \theta+i_{b n} \cos \left(\theta-120^{\circ}\right)+i_{c n} \cos \left(\theta-240^{\circ}\right)\right] \\
& i_{q n}=-\frac{2}{3}\left[i_{a n} \sin \theta+i_{b n} \sin \left(\theta-120^{\circ}\right)+i_{c n} \sin \left(\theta-240^{\circ}\right)\right]
\end{aligned}
$$

The dq0 flux linkage components:

$$
\begin{aligned}
& \psi_{d n}=-\left(L_{a d n}+L_{1 \mathbf{n}}\right) i_{d n}+L_{a d n} i_{f d n}+L_{a d n} i_{1 d n} \\
& \psi_{q n}=-\left(L_{a q n}+L_{\mathbf{l n}}\right) i_{q n}+L_{a q n} i_{1 q n}+L_{a q n} i_{2 q n}
\end{aligned}
$$

So, any change in stator flux linkages and current components changeges $T_{e n}$. The change in $T_{e n}$ can be expressed by the equation (12).

$$
\begin{aligned}
& \Delta \mathrm{T}_{\mathrm{en}}=\mathrm{K}_{\mathrm{sn}} \Delta \delta_{\mathrm{n}} \\
& K_{s}=\frac{E_{a m} E_{b}}{X_{T}} \cos \delta_{0}
\end{aligned}
$$

Where, $\delta_{n}=$ rotor angle, $\mathrm{K}_{\mathrm{sn}}=$ synchronizing torque coefficient. For simplification of calculation, here the change in field flux is considered negligible. The natural frequency of the generator can be represented by:

$$
\omega_{n} \infty \sqrt{K_{s}}
$$

\begin{tabular}{|c|c|c|c|c|c|}
\hline$P_{t}$ & $\begin{array}{l}\text { Real power in pu at } \\
\text { generator terminal }\end{array}$ & $\delta_{t b}$ & $\begin{array}{l}\text { angle between generator terminal and } \\
\text { infinite bus }\end{array}$ & $R_{L}$ & Line resistance in p.u. \\
\hline$Q_{t}$ & $\begin{array}{l}\text { Reactive power output from } \\
\text { generator }\end{array}$ & $A_{\text {sat }}$ & Magnetic saturation constant & $X_{t}$ & Transformer winding reactance in p.u. \\
\hline $\mathrm{E}_{\mathrm{a}}$ & Generator internal voltage & $B_{\text {sat }}$ & Magnetic saturation constant & $X_{L}$ & Line reactance in p.u. \\
\hline $\mathrm{E}_{\mathrm{am}}$ & $\begin{array}{l}\text { magnitude of generator } \\
\text { internal voltage }\end{array}$ & $\phi_{i}$ & angle of $I_{t}$, considering $E_{t}$ as reference & $X_{l}$ & Generator Leakage reactance in p.u. \\
\hline$E_{t}$ & $\begin{array}{l}\text { Generator terminal voltage } \\
\text { in pu }\end{array}$ & $\delta_{i}$ & $\begin{array}{l}\text { angle between terminal voltage and q- } \\
\text { axis }\end{array}$ & $X_{d}$ & Generator d-axis reactance in p.u. \\
\hline$E_{b}$ & Infinite bus voltage in pu & $\delta_{0}$ & Steady state rotor angle & $X_{q}$ & Generator q-axis reactance in p.u. \\
\hline $\mathrm{I}_{\mathrm{t}}$ & $\begin{array}{l}\text { Generator stator current } \\
\text { considering Et as reference }\end{array}$ & $R_{a}$ & Generator armature resistance in p.u. & $\mathrm{K}_{\mathrm{sd}}$ & degree of magnetic saturation in d-axis \\
\hline $\mathrm{I}_{\mathrm{m}}$ & $\begin{array}{l}\text { magnitude of generator } \\
\text { internal current }\end{array}$ & $R_{t}$ & Transformer winding resistance in p.u. & $\mathrm{K}_{\mathrm{sq}}$ & degree of magnetic saturation in q-axis \\
\hline$X_{a q u}$ & \multicolumn{5}{|c|}{ Unsaturated mutual reactance between stator and q-axis rotor circuit } \\
\hline$X_{a q u}$ & \multicolumn{5}{|c|}{ Unsaturated mutual reactance between stator and q-axis rotor circuit } \\
\hline$X_{d}^{\prime}$ & \multicolumn{5}{|c|}{ Generator d-axis transient reactance in pu } \\
\hline
\end{tabular}

So to calculate the natural frequency of the T-G shaft, $K_{\mathrm{s}}$ will be used. To calculate $K_{\mathrm{s}}$, consider the single-line diagram in Fig. 3 which will be used to find the torsional frequencies of T-G shaft. The calculation of $K_{\mathrm{s}}$ is done by graphical equations in Fig. 4, where the following nomenclatures are used.

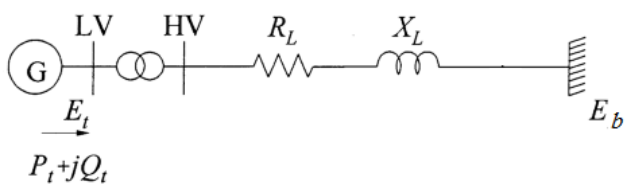

Fig. 3 

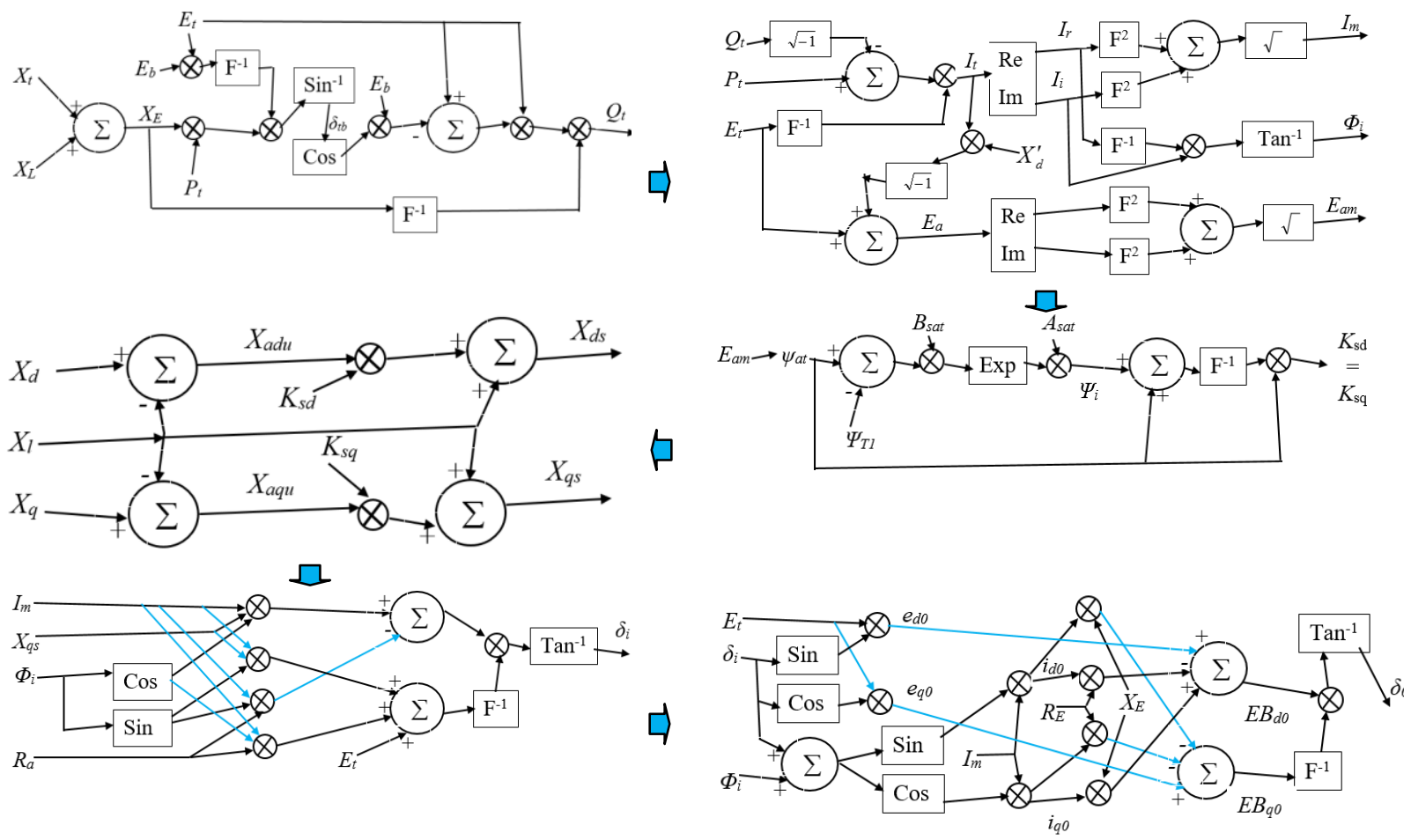

$$
\begin{aligned}
X_{E} & =X_{t}+X_{L} \\
R_{E} & =R_{t}+R_{L} \\
X_{T} & =X_{t}+X_{L}+X_{d}^{\prime} \\
\psi_{\mathrm{at}} & =\mathrm{E}_{\mathrm{am}}
\end{aligned}
$$

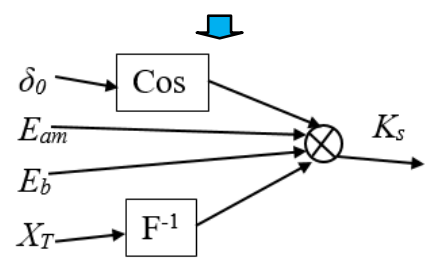

\section{T-G Shaft System}

Fig. 4

The natural frequencies of T-G shaft masses are in super and SSF ranges. The number of torsional vibrational modes and its frequencies depend on the number of masses, its physical and dynamic parameters. The stimulating problem due to interaction between rotor mechanical and electrical systems is in the SSF range. For investigating the interaction between nonlinear loads and rotating masses, a simle lumped-mass model of the T-G shaft is considered [ 14]. Fig. 5 shows five torsional masses; a high-pressure (HP) stage, an intermediate-pressure (IP), two low-pressure (LP ${ }_{A}$ and $\mathrm{LP}_{\mathrm{B}}$ ) stages, and a Generator having static exciter. This system has been used to investigate the excitation of torsional oscillations.

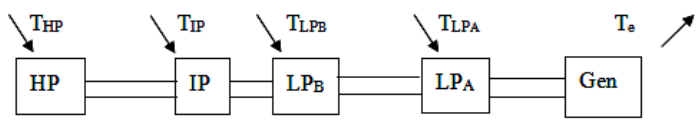

Fig. 5. Structure of a typical lumped-mass shaft system

The dynamics of any mass can be modeled by mathematical equations (15) and (16).

$$
\begin{aligned}
& 2 H_{j} \frac{d \Delta \omega_{j}}{d t}=T_{j}+K_{j, j+1}\left(\delta_{j+1}-\delta_{j}\right)-K_{j-1, j}\left(\delta_{j}-\delta_{j-1}\right)-D_{j}\left(\Delta \omega_{j}\right) \\
& \frac{d \delta_{j}}{d t}=\omega_{0} \Delta \omega_{j}
\end{aligned}
$$

where, $j=1$ to $5 . T_{l}=-T_{e}, T_{2}=T_{L P A}, T_{3}=T_{L P B}, T_{4}=T_{I P}, T_{5}=T_{H P}, H=$ mass inertia, $K=$ rigidity coefficient, $D=$ damping factor, $\omega=$ shaft speed, $\delta=$ rotor angle. Electromagnetic torque, during transient condition, is determined by the dynamics of the generator and the power system. The torsional torques associated with each section of turbine shaft depend on the dynamics of the turbine and its governing system.

The torsional frequencies and its mode shapes can be derived by using eigenvalue analysis technique. For this, the equations of complete shaft system have to be expressed in state-space form as follows:

$$
\begin{aligned}
& \dot{x}=A x+B u \\
& y=C x+D u
\end{aligned}
$$


where, $x$ is the state vector, $y$ is the output vector, $u$ is the input vector, $A$ is the state matrix, $B$ is the control matrix, $C$ is the output matrix, $D$ is the feedforward matrix.

Accordingly, the state-space form of equations (15) and (16) is obtained by linearizing them. For certain load conditions, the change in mechanical torques can be considered zero. The change in electrical torque is not zero, and it was shown by equation (12). The state-space form can be expressed in matrix form, as in equation (19), where $\boldsymbol{A}$ is the plant matrix and $\boldsymbol{A}=f\left(H, D, K, K_{s}\right)$.

\begin{tabular}{|c|c|c|c|c|c|c|c|c|c|c|c|}
\hline & $-\frac{D_{1}}{2 H_{1}}$ & $\frac{K_{12}+K_{s}}{2 H_{1}}$ & 0 & $\frac{K_{12}}{2 H_{1}}$ & 0 & 0 & 0 & 0 & 0 & 0 & \\
\hline$\Delta \omega_{1}$ & $\omega_{0}$ & 0 & 0 & 0 & 0 & 0 & 0 & 0 & 0 & 0 & $\Delta \omega_{1}$ \\
\hline$\Delta \delta_{1}$ & 0 & $\frac{K_{12}}{2 H}$ & $\frac{D_{2}}{2 H}$ & $\frac{K_{12}+K_{23}}{2 H}$ & 0 & $\frac{K_{23}}{2 H}$ & 0 & 0 & 0 & 0 & $\Delta \delta_{1}$ \\
\hline $\begin{array}{l}\Delta \omega_{2} \\
\Delta \dot{\delta}\end{array}$ & 0 & $\begin{array}{c}2 \mathrm{H}_{2} \\
0\end{array}$ & $\begin{array}{l}2 \mathrm{H}_{2} \\
\omega_{0}\end{array}$ & $\begin{array}{l}2 \mathrm{H}_{2} \\
0\end{array}$ & 0 & $\begin{array}{c}2 \mathrm{H}_{2} \\
0\end{array}$ & 0 & 0 & 0 & 0 & $\Delta \omega_{2}$ \\
\hline $\begin{array}{l}\Delta o_{2} \\
\Delta \dot{\omega}_{2}\end{array}$ & 0 & . & $\omega_{0}$ & $K_{23}$ & $D_{3}$ & $K_{23}+K_{34}$ & 0 & $K_{34}$ & 0 & 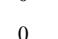 & \\
\hline$\Delta \dot{\delta}_{2}$ & & & & $\overline{2 \mathrm{H}_{3}}$ & $\overline{2 H_{3}}$ & $2 \mathrm{H}_{3}$ & & $\overline{2 \mathrm{H}_{3}}$ & 0 & & \\
\hline$\Delta O_{3}$ & 0 & 0 & 0 & 0 & $\omega_{0}$ & 0 & 0 & 0 & 0 & 0 & $\mathrm{O}_{3}$ \\
\hline$\Delta \omega_{4}$ & 0 & 0 & 0 & 0 & 0 & $K_{34}$ & $\frac{D_{4}}{2}$ & $K_{34}+K_{45}$ & 0 & $\frac{K_{45}}{2}$ & $\Delta \omega_{4}$ \\
\hline$\Delta \delta_{4}$ & & & & & & $2 \mathrm{H}_{4}$ & $2 \mathrm{H}_{4}$ & $2 \mathrm{H}_{4}$ & & $2 \mathrm{H}_{4}$ & $\Delta \delta_{4}$ \\
\hline$\Delta \dot{\omega}_{5}$ & 0 & 0 & 0 & 0 & 0 & 0 & $\omega_{0}$ & 0 & 0 & 0 & $\Delta \omega_{5}$ \\
\hline$\Delta \dot{\delta}_{5}$ & 0 & 0 & 0 & 0 & 0 & 0 & 0 & $\frac{K_{45}}{2 H}$ & $\frac{D_{5}}{2 H_{5}}$ & $-\frac{K_{45}}{2 H}$ & $\Delta \delta_{5}$ \\
\hline & 0 & 0 & 0 & 0 & 0 & 0 & 0 & 0 & $\omega_{0}$ & 0 & \\
\hline
\end{tabular}

in short form

$$
\left[\begin{array}{c}
\Delta \dot{\omega}_{i} \\
\Delta \dot{\delta}_{i}
\end{array}\right]=\boldsymbol{A}\left[\begin{array}{c}
\Delta \omega_{i} \\
\Delta \delta_{i}
\end{array}\right]
$$

The eigenvalues and eigenvectors of $\boldsymbol{A}$ have been calculated using eigenvalue analysis technique with MATLAB simulation tool. As the T-G shaft has five masses, there are five modes of torsional oscillation. The mode frequencies are calculated from imaginary part of eiginevalues, shwon in Table I. The relative rotational displancements (right eigenvectors associated to either speed deviations or the angle deviations) of individual masses for each mode of oscillation are shown in Fig. 6.

TABLE I

SIMULATION RESULTS OF STATE MATRIXA

\begin{tabular}{|c|c|c|c|}
\hline \multicolumn{2}{|c|}{ Eigenvalues $\lambda$} & $\begin{array}{c}\text { Mode } \\
\text { Frequency } \\
(\text { Hz) }\end{array}$ & $\begin{array}{c}\text { Torsional } \\
\text { Mode }\end{array}$ \\
\hline$\lambda_{1,2}$ & $-0.6931652 \pm 85.44842383 \mathrm{i}$ & 45.4 & 4 \\
\hline$\lambda_{3,4}$ & $-0.5566807 \pm 96.73304251 \mathrm{i}$ & 31.3 & 3 \\
\hline$\lambda_{5,6}$ & $-0.6441085 \pm 56.21256768 \mathrm{i}$ & 24.9 & 2 \\
\hline$\lambda_{7,8}$ & $-0.3551595 \pm 05.42518046 \mathrm{i}$ & 16.8 & 1 \\
\hline$\lambda_{9,10}$ & $-0.4069221 \pm .4898816350 \mathrm{i}$ & 0.55 & $\begin{array}{c}0 \\
\text { (system } \\
\text { mode) }\end{array}$ \\
\hline
\end{tabular}

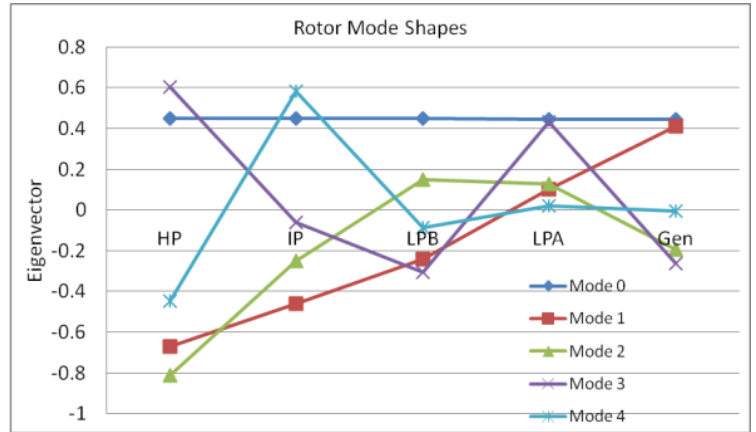

Fig. 6

The mode 0 represents the oscillation of the entire rotor against the power system. It depends on the total inertia constant of all rotor masses and synchronizing torque coefficient $K_{s}$. From Fig. 6, it is seen that all masses take part nearly equally in mode 0 . Modes 1 to 4 represent the torsional mode of oscillation. Mode 1 hase one polarity reversal where polarities of eigenvector associated with generator and LP A are opposite to those assiciated to $\mathrm{LP}_{\mathrm{B}}$, IP and HP sections. This indicates that if mode 1 is excited, generator and LP ${ }_{\mathrm{A}}$ oscillate against other three masses. Mode 2 has two polarity reversals, Mode 3 has three polarity reversals and Mode 4 has four polarity reversals. In Mode 4, there is very low relative amplitudes of rotational displacement between generator and $\mathrm{LP}_{\mathrm{A}}$. This indicates this mode can not be easily excited.

\section{Test System}

For assessing ATOTs, a test system having a synchronous generator supplying power to an EAF and infinite bus, is considered.

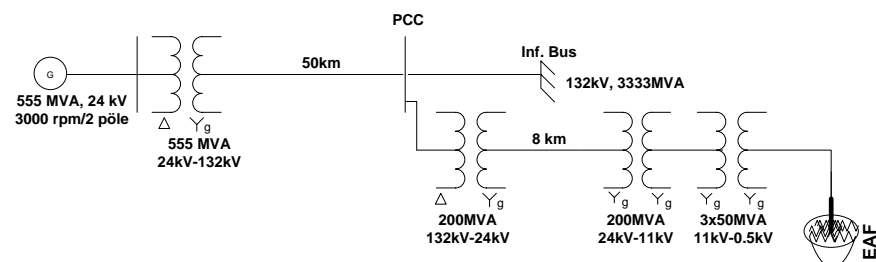

Fig. 7.Test system 


\section{A. Description of The Test System}

The electromechanical system shown in Fig. 7 is used to analyse TR in T-G shaft due to operation of EAF. The steam turbine unit has 4 stages shown in Fig. 5. In the simulation, the speed governing system is used which is not shown in Fig. 7. The speed governing system includes a speed relay, a proportional regulator, and a servomotor which controls the gate opening. Turbine power is distributed in fractions to various shaft stages. The turbine shaft is coupled to the masses including the synchronous generator resulting in total five masses. Table II, III, IV shows parameters of T-G shaft, generator's electrical parameters, line parameters respectively. Terminal voltage of the generator is controled by a static exciter.

TABLE II

$D, H, K$ VALUES OF MASSES IN T-G SHAFT

\begin{tabular}{|c|c|c|c|}
\hline Element & $\begin{array}{c}\boldsymbol{D} \\
\text { (pu torque / pu } \\
\text { speed deviation) }\end{array}$ & $\begin{array}{c}\boldsymbol{K} \\
\text { (pu torque } \\
\text { /electr.rad.) }\end{array}$ & $\begin{array}{c}\boldsymbol{H} \\
\text { (MW-s /MVA) }\end{array}$ \\
\hline Generator & 0.16 & -- & 0.556 \\
\hline $\mathrm{LP}_{\mathrm{A}}$ & 2.4832 & 51.92 & 0.775 \\
\hline $\mathrm{LP}_{\mathrm{B}}$ & 0.40 & 63 & 0.751 \\
\hline $\mathrm{IP}$ & 0.40 & 40.33 & 0.151 \\
\hline $\mathrm{HP}$ & 0.32 & 18.17 & 0.081 \\
\hline
\end{tabular}

TABLE III

GENERATOR DATA OF THE TEST SYSTEM

\begin{tabular}{|c|c|c|c|}
\hline Parameters & Value (PU) & Parameters & Value \\
\hline $\mathrm{Xd}$ & 1.51 & $\mathrm{Xl}$ & $0.13 \mathrm{pu}$ \\
\hline $\mathrm{Xd}$ & 0.257 & $\mathrm{R}_{a}$ & $0.003 \mathrm{pu}$ \\
\hline $\mathrm{Xd}$ & 0.203 & $\mathrm{Tdo}^{\prime}$ & $8.1 \mathrm{~s}$ \\
\hline $\mathrm{Xq}$ & 1.47 & Tdo" $^{\prime}$ & $0.0335 \mathrm{~s}$ \\
\hline $\mathrm{Xq}$ & 0.6 & Tqo' $^{\prime}$ & $1.06 \mathrm{~s}$ \\
\hline $\mathrm{Xq} "$ & 0.229 & Tqo" & $0.08 \mathrm{~s}$ \\
\hline
\end{tabular}

TABLE IV

COMPONENTS OF LINE IMPEDANCE

\begin{tabular}{|c|c|c|c|}
\hline Sequences & $\begin{array}{c}\text { Resistance } \\
(\mathbf{O h m} / \mathbf{k m})\end{array}$ & $\begin{array}{c}\text { Inductance } \\
(\mathbf{H} / \mathbf{k m})\end{array}$ & $\begin{array}{c}\text { Capacitance } \\
(\mathbf{F} / \mathbf{k m})\end{array}$ \\
\hline Positive & 0.01165 & $0.8679 \mathrm{e}-3$ & $13.41 \mathrm{e}-9$ \\
\hline Zero & 0.2676 & $3.008 \mathrm{e}-3$ & $8.57 \mathrm{e}-9$ \\
\hline
\end{tabular}

The steel industry is located at $8 \mathrm{~km}$ distance from PCC (at $132 \mathrm{kV}$ bus) and using EAF to pruduce steel. Other transformers, between PCC and EAF are shown in Fig. 7 with ratings. These transformers are used to step down the voltages to operating levels of EAF. The EAF is designed as single phase furnace and three single phase furnaces, behaving as three phase EAF, are connected to three phases of $24 \mathrm{kV} / 11 \mathrm{kV}, 200 \mathrm{MVA}, 3-\phi$ transformer through single phase transformers. The impedances of the three-phase transformers are $0.008+\mathrm{j} 0.13 \mathrm{pu}$ and $0.0006+\mathrm{j} 0.13 \mathrm{pu}$, respectively.

\section{B. Mode Frequencies of T-G Shaft Using FFT}

The TOT signals are obtained from simulink and analysed using FFT. From FFT, shown in Fig. 8, we see that the mode frequencies of torsional torques are are $1.2,16.8,24.9,31.3,45.4 \mathrm{~Hz}$ which are similar to frequencies that of obtained using eigenvalue analysis in Table I. The only error is in mode 0 . This error arises, may be, becuase of different assumptions in deriving performance equations of generator. Fig. 8 shows that torsional frequencies between generator-LA section and HP-IP section are same because same oscillating torques are transmitted through the rotor masses. This proof of having same frequency using two different techniques will ensure validity of mode frequencies obtained using FFT in simulink when there will be more than one generator in the system. Because eigenvalue analysis technique becomes cumbersome with more generators in the system. Whereas, no mater how many of generators in the system, it is easy to obtain their mode frequencies using MATLAB simulink and power library.

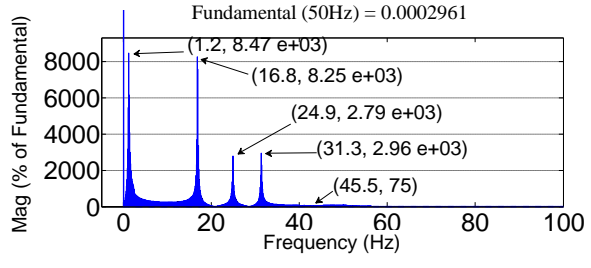

(a) at generator- $\mathrm{LP}_{\mathrm{A}}$ section

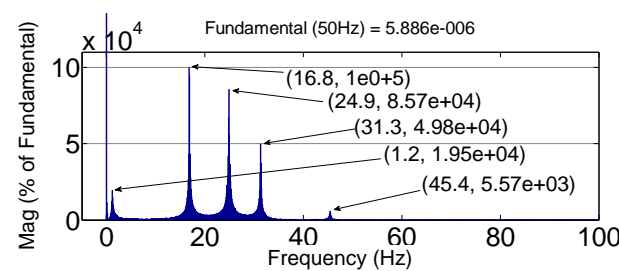

(b) at HP-IP section

Fig. 8. FFT of torsional torque

\section{Simulation Results}

Here, the deterministic model of EAF has been used and the necessary outputs of the simulation are expounded to converge the objective of this paper.

\section{A. Feeder Voltage and Current}

The arc length as well as arc resistance changes continuously because when scraps melt, the position of electrodes changes. From operating principle, the arc voltage need to be increased precipitately to arc ignition 
point, Fig. 9(a). The EAF then can be represented as an equivalent open circuit although a very small leakage current flows through foamy slag. At this time, the arc resistance is very high as shown by the impulses in Fig. 9(b)

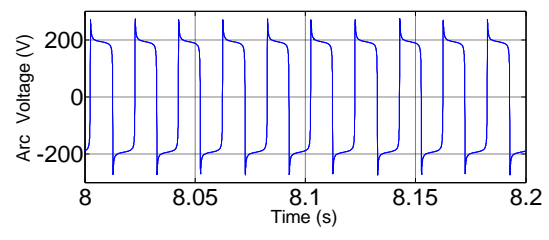

(a)

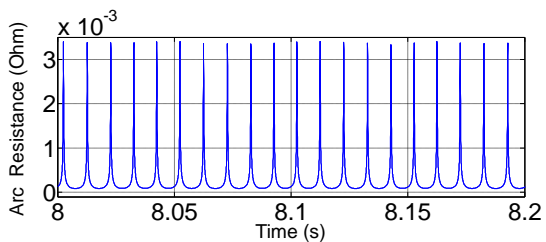

(b)

Fig. 9. (a) Arc voltage in volts, (b) arc resistance in ohm

During arc establishment, there occurs a transient process and the arc voltage drops exponentially from ignition point. The electrodes and scrap materials become short circuited, so the arc resistance becomes very negligible. When the scraps melt completely, the arc is extinguished and the voltage drops to arc extinction point.

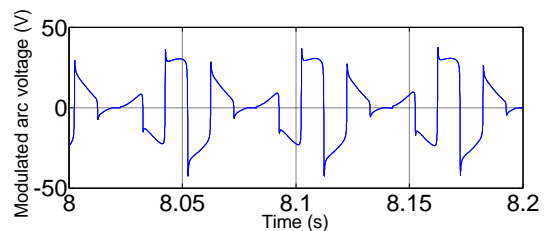

(a)

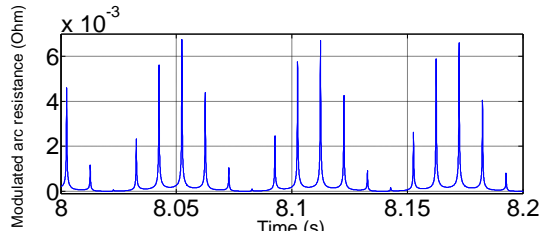

(b)

Fig. 10. (a) Modulated arc voltage in volts, (b) modulated arc resistance in ohm

In the deterministic model of arc, resistance is varied sinusoidally to obtain the similar characteristic of a practical EAF load. During variation of arc resistance a $16.8 \mathrm{~Hz}$ signal along $60 \%$ modulation index is chosen in the simulation. Fig. 10 shows the modulated arc resistance and arc voltage.

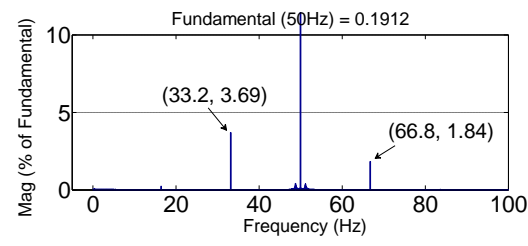

(a)

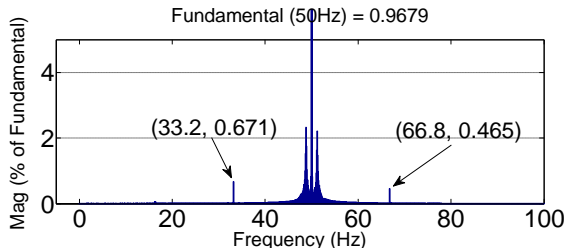

(b)

Fig. 11.(a) FFT of feeder current $i_{a}$ at furnace transformer, (b) FFT of $i_{a}$ at PCC

Fig. 11(a), (b), show two frequencies $33.2 \mathrm{~Hz}$ and $66.8 \mathrm{~Hz}$ because $16.8 \mathrm{~Hz}$ signal was impregnated during resistance modulation. For this reason, the furnace feeder is considered as the source of super and SSFs and the EAF can be considered as the source current which disturbs the synchronous generator.

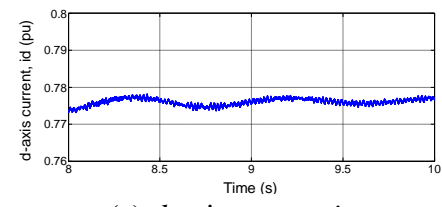

(a) $d$-axis current $i_{d}$

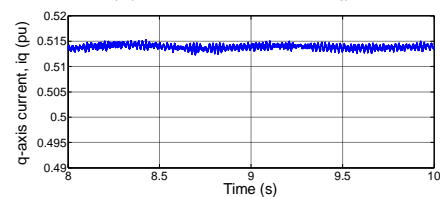

(c) $q$-axis current $i_{q}$

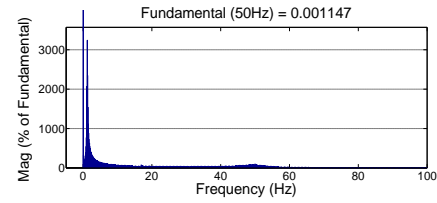

(b) FFT of $i_{d}$

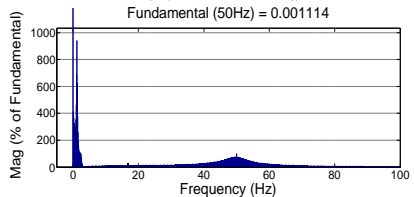

(d) FFT of $i$

Fig. 12. $d$-and $q$-axis current components without EAF in the system

\section{B. dq0 Current Components}

Fig. 12 shows $d$-and $q$-axis current components and their FFTs. These $d$-and $q$-axis current components are obtained from the simulation when there are no EAFs in the system. From Fig. 12(a), (c), it is seen that $d$ and $q$-axis current appear almost constant with negligible variation around the constant DC value. From their 
FFTs, shown in Fig. 12(b), (d), it is seen that there are no dominant frequency components other than DC component. It proves that the system is running in steady-state condition and stator currents contain no super/SSFs.

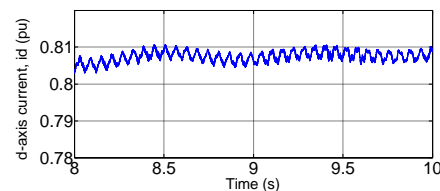

(a) $d$-axis current $i_{d}$

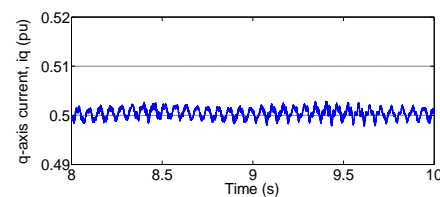

(c) $q$-axis current $i_{q}$

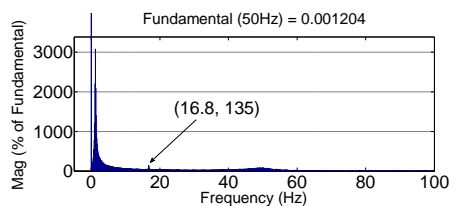

(b) FFT of $i_{d}$

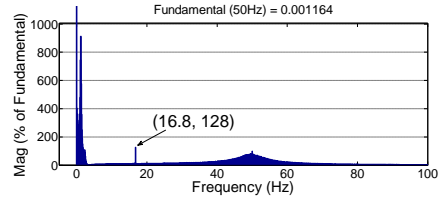

(d) FFT of $i$

13. $d$ - and $q$-axis current components Fig with EAF in the system

Fig. 13 explain s the $d q$-axis current component s with EAF in the system. Since the frequency of the modulating signal is $16.8 \mathrm{~Hz}$, it is seen in Fig. 13(b), (d) which also prove of having $16.8 \mathrm{~Hz}$ frequency component as dominant. Comparing $d q$-axis current components in Fig. 12(a), (c) with $d q$-axis currents in Fig. 13(a), (c), it is deducible that amplitude of oscillation of $d q$-axis currents are larger with EAF.

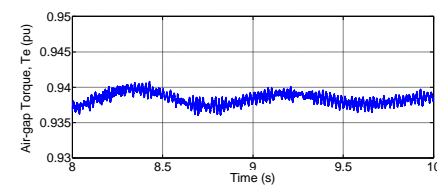

(a) $T_{e}$ at no resonance

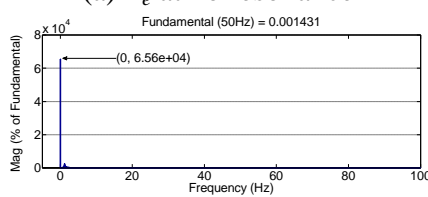

(b) FFT of $T_{e}$

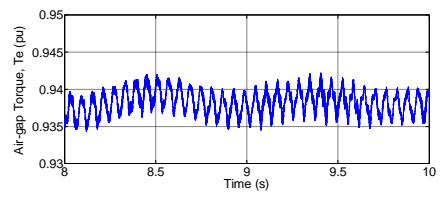

(c) $T_{\mathrm{e} 1}$ at resonance with $16.8 \mathrm{~Hz}$

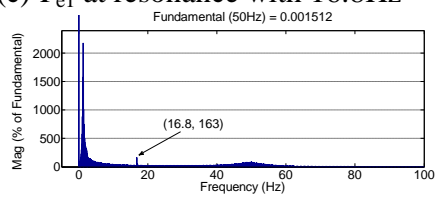

(d) FFT of $T_{\mathrm{e} 1}$

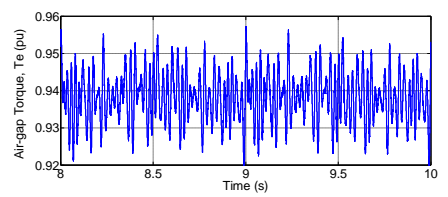

(e) $T_{\mathrm{e} 2}$ at more frequencies from $\mathrm{EAF}$

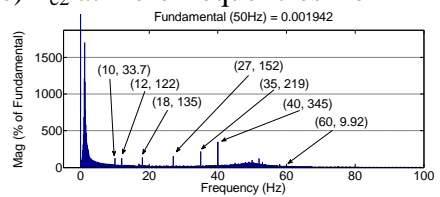

(f) FFT of $T_{\mathrm{e} 2}$

Fig. 14. Electromagnetic torque with EAF in the system

\section{Electromagnetic Torque:}

The impact harmonic currents from feeder currents on electromagnetic torque $T_{\mathrm{e}}$ is shown in Fig. 14. When there occurs no resonace, Fig. 14(a), we see a small amplitude oscillation of $T_{\mathrm{e}}$ which may be due to small variation in input mechanical power. Fig. 14(b) shows that there is no frquency component as dominant other than DC value. But when there occurs resonance, $T_{\mathrm{e}}$ is perturbed and its amplitude variation is augmented as shown in Fig. 14(c), (e). This increasing oscillation is the result of perturbation of $d q$-axis currents due to current components of SSFs. This indicates that any SSFs generated in power system may augment $T_{\mathrm{e}}$. Fig. 14(d), (f) prove of having those SSFs produced by EAF.

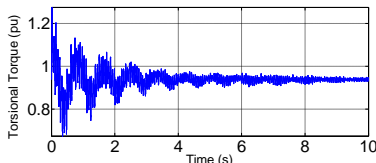

(a) no resonance at generatorLPA

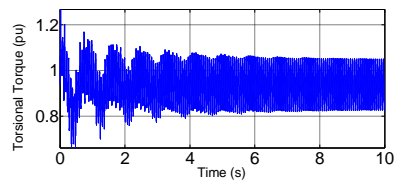

(b) resonance at generator-LPA

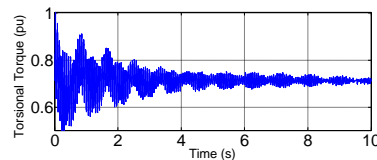

(c) no resonance at LPA-LPB

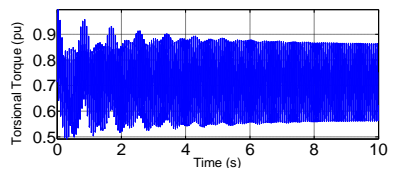

(d) resonance at LPA-LPB

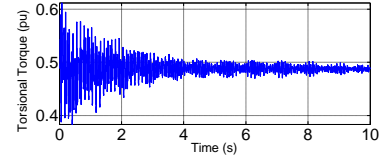

(e) no resonance at LPB-IP

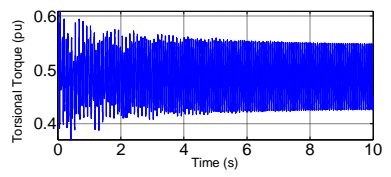

(f) resonance at LPB-IP

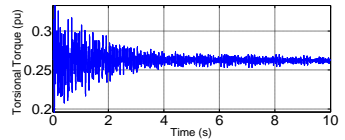

(g) no resonance at IP-HP

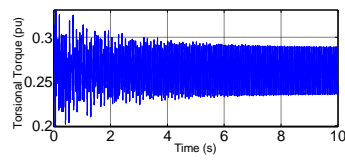

(h) resonance at IP-HP

Fig. 15. Torsional torque transmission in T-G mass sections

\section{Torsional Torque Amplification:}

The torsional torques between different mass sections are shown in Fig. 15. Where, Fig. 15(a), (c), (e), (g) represent the transmitted torque when there is a EAF in the power system but occurs no resonance. They also 
show that the torsional torques reach to a steady value after 8 seconds of starting generator. Fig. 15(b), (d), (f), (h) represent the resonant excitation of the transmitted torque. They show amplification of TOTs and it is seen that amplitude of TOTs derease as they proceed toward HP from generator.

\section{Torsional Torque Quantification}

For computing amplification of TOTs, each of steady and TOTs between masses has been analysed using FFT tools. Actually the torsional modes are variations of TOTs around its steady value. A pradigm of obtaining amplification of TOTs between generator- $\mathrm{LP}_{\mathrm{A}}$ section is described here using FFT analysis technique. At first, the TOTs of mode 1 at nonresonance is measured from the simulation and found as $\quad a=0.02533 \mathrm{pu}$. Then, a $16.8 \mathrm{~Hz}$ resonance frquency is generated from the EAF, and TOTs of mode 1 is mesured as $b=0.11569$ pu. Now amplification of TOTs of mode 1 at gnerator-LPA section is $=b / a=4.57$ times, which is quite a large value.

For better comprehending the values of measured torques, they are represented by $T_{(L P A-G e n)}, T_{(L P B-L P A)}$, $T_{(I P-L P B)}$, and $T_{(H P-I P)}$, respectively. Table V-VI summerize nonresonant and resonant torsional torques, respectively, with one EAF. At nonresonance, EAF is assumed not to produce any frequency equal or closely equal to the torsional mode frequencies. At resonance the EAF is assumed to produce $16.8 \mathrm{~Hz}$ frequency which is equal to frquency of torsional mode 1 .

TABLE V

NON-RESONANT TORSIONAL TORQUES WHEN ONE EAF AT PCC

\begin{tabular}{|c|c|c|c|c|c|c|c|}
\hline $\begin{array}{r}\mathbf{f}(\mathrm{Hz}) \\
\text { Torque(put) }\end{array}$ & 0 & 1.2 & 16.8 & 24.9 & 31.3 & 45.4 & 50 \\
\hline$T_{(H P-I P)}$ & 0.26261 & 0.00116 & 0.00610 & 0.00522 & 0.00308 & 0.00036 & $6.179 \times 10^{-6}$ \\
\hline$T_{(I P \cdot L P B)}$ & 0.48931 & 0.00335 & \begin{tabular}{|l|}
0.01387 \\
\end{tabular} & 0.00820 & 0.00253 & 0.00051 & $1.729 \times 10^{-5}$ \\
\hline$T_{(L P B-L P A)}$ & 0.71382 & 0.01401 & \begin{tabular}{|l|}
0.03417 \\
\end{tabular} & 0.00092 & 0.01182 & 0.00013 & $5.449 \times 10^{-5}$ \\
\hline$T_{(L P A-G e n)}$ & 0.93856 & 0.02521 & \begin{tabular}{|l|}
0.02533 \\
\end{tabular} & 0.00854 & 0.00920 & \begin{tabular}{|l|}
0.00022 \\
\end{tabular} & $3.139 \times 10^{-4}$ \\
\hline
\end{tabular}

TABLE VI

RESONANT TORSIONAL TOROUE WHEN ONE EAF AT PCC

\begin{tabular}{|l|c|c|c|c|c|c|c|}
\hline $\begin{array}{c}\text { f(Hz) } \\
\text { Torque(pu) }\end{array}$ & $\mathbf{0}$ & $\mathbf{1 . 2}$ & $\mathbf{1 6 . 8}$ & $\mathbf{2 4 . 9}$ & $\mathbf{3 1 . 3}$ & $\mathbf{4 5 . 4}$ & $\mathbf{5 0}$ \\
\hline $\boldsymbol{T}_{(\text {HP-IP })}$ & 0.2621 & 0.0011 & 0.0278 & 0.0053 & 0.0031 & 0.0003 & $1.78 \times 10^{-5}$ \\
\hline $\boldsymbol{T}_{(I P-L P B)}$ & 0.4891 & 0.0033 & 0.0637 & 0.0083 & 0.0018 & 0.0005 & $2.47 \times 10^{-5}$ \\
\hline $\boldsymbol{T}_{(L P B-L P A)}$ & 0.7137 & 0.0138 & 0.1562 & 0.0007 & 0.0119 & 0.0002 & $1.12 \times 10^{-4}$ \\
\hline $\boldsymbol{T}_{(L P A-G e n)}$ & 0.9382 & 0.0250 & 0.1157 & 0.0085 & 0.0093 & 0.0002 & $2.88 \times 10^{-4}$ \\
\hline
\end{tabular}

TABLE VII

AMPLIFICATION OF MODE 1 WITH ONE EAF AT PCC

\begin{tabular}{|l|c|c|c|c|c|c|}
\hline $\begin{array}{l}\text { Torque } \\
\text { ratio between sections }\end{array}$ & $\mathbf{0}$ & $\mathbf{1 . 2}$ & $\mathbf{1 6 . 8}$ & $\mathbf{2 4 . 9}$ & $\mathbf{3 1 . 3}$ & $\mathbf{4 5 . 4}$ \\
\hline HP-IP & 0.9981 & 0.9767 & 4.5608 & 1.0120 & 1.0119 & 0.9652 \\
\hline $\mathbf{I P}_{-\mathbf{L P}}$ & 0.9995 & 0.9720 & 4.5956 & 1.0157 & 0.7153 & 0.9913 \\
\hline $\mathbf{L P}_{\mathbf{B}}-\mathbf{L P}$ & 0.9999 & 0.9872 & 4.5729 & 0.7604 & 1.0076 & 1.3149 \\
\hline $\mathbf{L P}_{\mathbf{A}}-\mathbf{G e n}$ & 0.9996 & 0.9922 & 4.5672 & 0.9978 & 1.0139 & 0.7111 \\
\hline
\end{tabular}

Data in Table VI have been compared to data in Table V and summerized in Table VII which shows that as the $16.8 \mathrm{~Hz}$ torsional mode is excited, the torsional torques are amplified relating to this mode only.

Others modes are not amplified. It is that the $16.8 \mathrm{~Hz}$ mode is amplifed on an average 4.57 times of its nonresonant condition.

\section{A. Torque due to Multiple Frequencies Produced in EAF}

In this part of simulation, arc resistance of EAF has been adapted so that the feeder becomes a current source of SSFs in the range of $0-45.5 \mathrm{~Hz}$. The combination of mode 0 , mode 0 and 1 , mode 0,1 and 2 , etc. have been chosen to simulate the network and their effects have been observed.

Table VIII(A) explain s amplification of TOT due to resonant excitation of different modes. It shows that if a mode is excited, the TOTs of the corresponding mode are amplified. It does not affect the TOTs corresponding to other modes. For example, if mode 2 is excited, only the TOTs corresponding to mode 2 are amplified. It is seen that the average amplification of TOT of mode 1 is 4.55 and that of mode 4 is 16.3 . So, it is deducible that if the higher mode is excited the amplification of TOT becomes higher.

\section{B. Torque due to Multiple EAFs at PCC}

In this part of simulation , at first, two EAFs of similar capacities and characteristics have been connected at the same PCC. For both EAFs, arc resistances can be adapted with signals of frequencies in the range of $0-45.5 \mathrm{~Hz}$, worst case conditions have been considered. For example, arc resistances of both EAFs have been varied by $16.8 \mathrm{~Hz}$ frequency signals to excite mode 1 . To excite other modes, EAFs have been adapted 
correspondingly. Table VIII(B) shows that the amplification of TOTs where its average value of mode 1 is 8.63 , and for mode 3 is 14.5 .

TABLE VIII

TORSIONAL TORQUE (MULTIPLE FREQUENCY TEST)

\begin{tabular}{|c|c|c|c|c|c|c|c|c|c|c|c|c|c|}
\hline \multirow[b]{2}{*}{$\begin{array}{l}\text { Resonance } \\
\text { Condition }\end{array}$} & \multirow[b]{2}{*}{$\begin{array}{l}f(\mathrm{~Hz}) \\
\text { Torque } \\
\text { ratio }\end{array}$} & \multicolumn{6}{|c|}{ (A) WITH ONE EAF AT PCC } & \multicolumn{6}{|c|}{ (B) WITH TWO EAFs AT PCC } \\
\hline & & $\mathbf{0}$ & 1.2 & 16.8 & 24.9 & 31.3 & 45.4 & $\mathbf{0}$ & 1.2 & 16.8 & 24.9 & 31.3 & 45.4 \\
\hline \multirow{4}{*}{$\begin{array}{c}\text { Resonant at } \\
1.2 \mathrm{~Hz}\end{array}$} & HP-IP & 0.9999 & 1.2451 & 1.1501 & 1.0510 & 0.9671 & 0.9629 & 0.9965 & 1.4643 & 0.5733 & 0.2695 & 0.8496 & 0.1118 \\
\hline & IP-LP $\mathbf{B}_{\mathrm{B}}$ & 1.0003 & 1.2506 & 1.1482 & 1.0486 & 0.9671 & 0.9619 & 1.0061 & 1.4809 & 0.5751 & 0.2695 & 0.8481 & 0.1129 \\
\hline & $\mathbf{L P} \mathbf{P}_{\mathrm{B}}-\mathbf{L} \mathbf{P}_{\mathrm{A}}$ & 0.9999 & 1.2497 & 1.1493 & 1.0398 & 0.9649 & 1.0088 & 0.9984 & 1.4882 & 0.5757 & 0.2771 & 0.8527 & 0.8938 \\
\hline & $\mathbf{L P}_{\mathrm{A}}$-Gen & 1.0000 & 1.2470 & 1.1465 & 1.0389 & 0.9894 & 1.0001 & 0.9986 & 1.4872 & 0.6171 & 0.2611 & 0.7524 & 1.0902 \\
\hline \multirow{4}{*}{$\begin{array}{c}\text { Resonant at } \\
1.2 \text { and } \\
16.8 \mathrm{~Hz}\end{array}$} & HP-IP & 0.9999 & 1.2230 & 4.6959 & 1.0617 & 0.9450 & 0.9359 & 0.9983 & 1.4394 & 8.6193 & 1.1236 & 1.0122 & 0.9593 \\
\hline & IP-LP B $_{\mathrm{B}}$ & 1.0007 & 1.2279 & 4.7054 & 1.0622 & 0.9461 & 0.9387 & 1.0039 & 1.4396 & 8.6454 & 1.1281 & 1.0217 & 0.9868 \\
\hline & $\mathbf{L} \mathbf{P}_{\mathrm{B}}-\mathbf{L} \mathbf{P}_{\mathrm{A}}$ & 0.9993 & 1.2332 & 4.7037 & 7.9263 & 0.9386 & 1.3828 & 0.9979 & 1.4565 & 8.6348 & 0.7225 & 1.0011 & 1.9161 \\
\hline & $\mathrm{LP}_{\mathrm{A}}$-Gen & 0.9981 & 1.2470 & 4.6999 & 1.0371 & 0.8735 & 0.7446 & 0.9988 & 1.4759 & 8.6217 & 1.0939 & 1.0114 & 0.5032 \\
\hline \multirow{4}{*}{$\begin{array}{c}\text { Resonant at } \\
1.2,16.8 \\
\text { and } 24.9 \mathrm{~Hz}\end{array}$} & \begin{tabular}{|l|} 
HP-IP \\
\end{tabular} & 0.9988 & 1.2611 & 4.1753 & 6.9034 & 1.1064 & 1.0678 & 1.0015 & 1.4521 & 8.6619 & 12.4713 & 0.9624 & 0.9454 \\
\hline & IP-LP B $_{\text {. }}$ & 0.9998 & 1.2469 & \begin{tabular}{|l|}
4.1732 \\
\end{tabular} & 6.8928 & 1.0942 & 1.1006 & \begin{tabular}{l|l|}
0.9987 \\
\end{tabular} & 1.4458 & 8.6614 & 12.4462 & 0.9398 & 0.8375 \\
\hline & $\mathbf{L P} \mathbf{P}_{\mathrm{B}}-\mathbf{L} \mathbf{P}_{\mathrm{A}}$ & 1.0003 & 1.2343 & \begin{tabular}{|l|}
4.1829 \\
\end{tabular} & 6.7521 & 1.1197 & 1.6126 & 0.9996 & 1.4472 & 8.6647 & 12.1719 & 0.9876 & 2.0039 \\
\hline & $\mathbf{L P}_{\mathrm{A}}$-Gen & 1.0009 & 1.2424 & 4.1849 & 6.8094 & 1.0262 & 1.0264 & 0.9983 & 1.4774 & 8.6583 & 12.3875 & 1.0171 & 0.0561 \\
\hline \multirow{4}{*}{$\begin{array}{c}\text { Resonant at } \\
1.2,16.8 \text {, } \\
24.9 \text { and } \\
31.3 \mathrm{~Hz}\end{array}$} & HP-IP & 0.9965 & 1.2168 & 4.7132 & 6.8807 & 7.5277 & 0.9568 & 1.0018 & 1.4267 & 8.6506 & 12.4908 & 16.0548 & 0.9903 \\
\hline & IP-LP B $_{\mathrm{B}}$ & 1.0023 & 1.2277 & 4.7151 & 6.8908 & 7.5137 & 0.8781 & 0.9999 & 1.4356 & 8.6637 & 12.4668 & 14.2849 & 0.8532 \\
\hline & $\mathbf{L P} \mathbf{P}_{\mathrm{B}}-\mathbf{L} \mathbf{P}_{\mathrm{A}}$ & 0.9963 & 1.2345 & 4.7140 & 6.5699 & 7.5345 & 0.8672 & 1.0013 & 1.4639 & 8.6058 & 11.7248 & 14.3422 & 0.8043 \\
\hline & $L_{P_{A}}$-Gen & 0.9998 & 1.2459 & 4.7159 & 6.9106 & 7.5495 & 0.9508 & 0.9982 & 1.4667 & 8.6335 & 12.4202 & 14.3131 & 0.6949 \\
\hline \multirow{4}{*}{$\begin{array}{c}\text { Resonant at } \\
1.2,16.8, \\
24.9,31.3 \\
\text { and } 45.4 \mathrm{~Hz}\end{array}$} & HP-IP & 0.9979 & 1.2179 & 4.6594 & 6.8250 & 7.4777 & 15.4817 & 0.9989 & 1.4223 & 8.6106 & 12.4546 & 14.1932 & 27.5925 \\
\hline & IP-LP B $_{\text {B }}$ & 0.9971 & 1.2235 & 4.6549 & 6.8094 & 7.4518 & 15.4572 & 1.0032 & 1.4286 & 8.6339 & 12.4231 & 14.1482 & 27.5666 \\
\hline & $\mathbf{L} \mathbf{P}_{\mathrm{B}}-\mathbf{L} \mathbf{P}_{\mathrm{A}}$ & 0.9990 & 1.2352 & 4.6495 & 6.5065 & 7.4387 & 16.4603 & 0.9967 & 1.4557 & 8.5596 & 11.6589 & 14.2035 & 30.7109 \\
\hline & $\mathbf{L P}_{\mathrm{A}}$-Gen & 0.9998 & 1.2378 & 4.6379 & 6.8007 & 6.9361 & 17.6823 & 0.9968 & 1.4638 & 8.5891 & 12.3659 & 14.2113 & 33.2748 \\
\hline
\end{tabular}

The comparison of amplification of TOTs due to one and multiple EAFs at PCC have been compared in Table IX which shows that as the number of EAFs increase at the PCC there cause increased amplification of TOTs at T-G shaft. Fig. 16 shows average amplification of TOTs due to operation of multiple EAFs.

TABLE IX

COMPARISON OF TORQUE AMPLIFICATION

\begin{tabular}{|c|c|c|c|c|c|}
\hline Mode & One EAF & Two EAFs & Three EAFs & Four EAFs & Five EAFs \\
\hline 0 & 1.24 & 1.46 & 1.64 & 1.83 & 2.01 \\
\hline 1 & 4.55 & 8.63 & 12.42 & 15.86 & 19.48 \\
\hline 2 & 6.8 & 12.3 & 17.04 & 22.1 & 26.71 \\
\hline 3 & 7.4 & 14.5 & 19.65 & 24.61 & 29.82 \\
\hline 4 & 16.3 & 29.8 & 41.46 & 50.08 & 58.98 \\
\hline
\end{tabular}

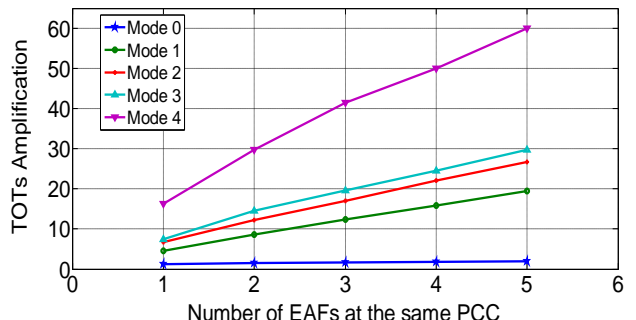

Fig. 16. ATOTs due to multiple EAFs at the same PCC

From Fig. 16 a set of polynomial equations , which correlate between amplification of TOTs and number of EAFs, can be obtained. The equations for different modes are as follows:

$$
\begin{aligned}
& \operatorname{ATOT}_{(m 4)}=0.1767 N^{3} e_{\text {eaf }}-2.4643 N^{2} \text { eaf }+19.979 N_{\text {eaf }}-1.456 \\
& \operatorname{ATOT}_{(m 3)}=0.1833 N^{3} e_{\text {eaf }}-1.9336 N^{2}{ }_{\text {eaf }}+11.523 N_{\text {eaf }}-2.354 \\
& \operatorname{ATOT}_{(m 2)}=0.0258 N^{3} \text { eaf }^{2}-0.3368 N^{2} \text { eaf }+6.1974 N_{\text {eaf }}+0.94 \\
& \operatorname{ATOT}_{(m 1)}=0.039 N^{3}{ }_{\text {eaf }}-0.4432 N^{2}{ }_{\text {eaf }}+5.1776 N_{\text {eaf }}-0.232 \\
& \operatorname{ATOT}_{(m 0)}=0.0025 N^{3} \text { eaf }-0.0275 N^{2}{ }_{\text {eaf }}+0.28 N_{\text {eaf }}+0.986
\end{aligned}
$$

where $N_{\text {eaf }}=$ number of EAFs connected to the same PCC. The constant coefficients in the equations may vary because the physical parameters for different network components are different. The trends of graph in Fig. 16 can be used to estimate amplification of TOTs for any mode of any number of EAFs at same PCC using respective mode equations. The trends also indicates the more the EAFs connected at same PCC and if TR occurs, the more the amplification of TOTs occurs.

\section{Torque due to Change in Location of EAF}

A simulation has been performed to check the impact of EAF on T-G shaft due to variation of location of EAF with respect to generator station. In this case, the distances between generator to PCC and PCC to 
infinite bus have been fixed to 10 and $70 \mathrm{~km}$ respectively. The distances between PCC to EAF have been chosen as $8,24,48,72 \mathrm{~km}$ etc.

The physical parameters of the component in the network and network structure have been considered same as before. The same SSFs 10,12, 18, 27, 35, $40 \mathrm{~Hz}$ are considered to be produced from EAF and nonresonant torsional torques between mass sections of the T-G shaft are measured. Then the torsional mode frequencies 1.2, 16.8, 24.9, 31.3 and $45.4 \mathrm{~Hz}$ are produced from the EAF, the amplified torsional torques are measured and compared to its non-resonant torsional torques. Table $\mathrm{X}$ shows the amplified torsional torques at different conditions.

TABLE X

TORSIONAL TORQUE AT RESONANCE WITH DISTANCE VARIATION BETWEEN EAF AND PCC

\begin{tabular}{|c|c|c|c|c|c|c|c|}
\hline $\begin{array}{c}\text { Distance } \\
\text { between } \\
\text { PCC and } \\
\text { EAF }\end{array}$ & $\begin{array}{l}\mathbf{f}(\mathrm{Hz}) \\
\begin{array}{l}\text { Torque } \\
\text { ratio }\end{array}\end{array}$ & $\mathbf{0}$ & 1.2 & 16.8 & 24.9 & 31.3 & 45.4 \\
\hline \multirow{4}{*}{$8 \mathrm{~km}$} & HP-IP & 1.0032 & 2.0433 & 13.7914 & 22.3051 & 28.9696 & 36.5161 \\
\hline & IP-LP $_{B}$ & 1.0028 & 2.0783 & 13.7823 & 22.2923 & 29.0697 & 36.5586 \\
\hline & $\mathbf{L P} \mathbf{P}_{\mathrm{B}}-\mathbf{L} \mathbf{P}_{\mathrm{A}}$ & 0.9989 & 2.1214 & 13.8187 & 21.4184 & 29.1944 & 41.10653 \\
\hline & $\mathbf{L P}_{\mathrm{A}}$-Gen & 0.9986 & 2.1385 & 13.7824 & 22.1646 & 28.9398 & 41.23327 \\
\hline \multirow{4}{*}{$24 \mathrm{~km}$} & HP-IP & 1.0026 & 1.5422 & 7.8541 & 12.609 & 16.2273 & 20.05941 \\
\hline & IP-LP $P_{B}$ & 1.0001 & 1.5694 & 7.8549 & 12.5738 & 16.2812 & 20.07923 \\
\hline & $\mathbf{L} \mathbf{P}_{\mathrm{B}}-\mathbf{L} \mathbf{P}_{\mathrm{A}}$ & 0.9997 & 1.5921 & 7.8923 & 12.1095 & 16.3598 & 22.57272 \\
\hline & $\mathbf{L P}_{\mathrm{A}}-\mathrm{Gen}$ & 1.0002 & 1.6016 & 7.8546 & 12.4774 & 16.1879 & 22.57228 \\
\hline \multirow{4}{*}{$48 \mathrm{~km}$} & HP-IP & 1.0058 & 1.2885 & 5.0048 & 7.8702 & 9.9876 & 12.19486 \\
\hline & IP-LP $_{B}$ & 1.0002 & 1.3089 & 4.9997 & 7.8091 & 10.0584 & 12.16279 \\
\hline & $\mathbf{L P} \mathbf{P}_{\mathrm{B}}-\mathbf{L} \mathbf{P}_{\mathrm{A}}$ & 0.9992 & 1.3215 & 5.0139 & 7.5782 & 10.0737 & 13.67278 \\
\hline & $\mathbf{L P}_{\mathrm{A}}$-Gen & 0.9988 & 1.3285 & 5.0053 & 7.7858 & 9.9769 & 13.66486 \\
\hline \multirow{4}{*}{$72 \mathrm{~km}$} & HP-IP & 1.0019 & 1.1815 & 3.7808 & 5.8398 & 7.377 & 8.89531 \\
\hline & IP-LP ${ }_{B}$ & 0.9976 & 1.1993 & 3.7806 & 5.7945 & 7.4049 & 8.94656 \\
\hline & $\mathbf{L P} \mathbf{P}_{\mathrm{B}}-\mathbf{L} \mathbf{P}_{\mathrm{A}}$ & 0.9994 & 1.2093 & 3.7986 & 5.621 & 7.4053 & 9.95642 \\
\hline & $L P_{A^{-}-G e n}$ & 1.0007 & 1.2137 & 3.7838 & 5.7673 & 7.3478 & 10.0024 \\
\hline
\end{tabular}

TABLE XI

AVERAGE TORQUE DUE TO DISTANCE VARIATION BETWEEN EAF AND PCC

\begin{tabular}{|l|c|c|c|c|}
\hline \multicolumn{1}{|c|}{ Distance } & $\mathbf{8} \mathbf{~ k m}$ & $\mathbf{2 4} \mathbf{~ k m}$ & $\mathbf{4 8} \mathbf{~ k m}$ & $\mathbf{7 2} \mathbf{~ k m}$ \\
\hline Torsional Modes & 2.1 & 1.58 & 1.31 & 1.2 \\
\hline Mode 0 & 13.79 & 7.86 & 5.01 & 3.79 \\
\hline Mode 1 & 22.05 & 12.44 & 7.76 & 5.76 \\
\hline Mode 2 & 29.04 & 16.26 & 10.02 & 7.38 \\
\hline Mode 3 & 38.85 & 21.32 & 12.92 & 9.45 \\
\hline Mode 4
\end{tabular}

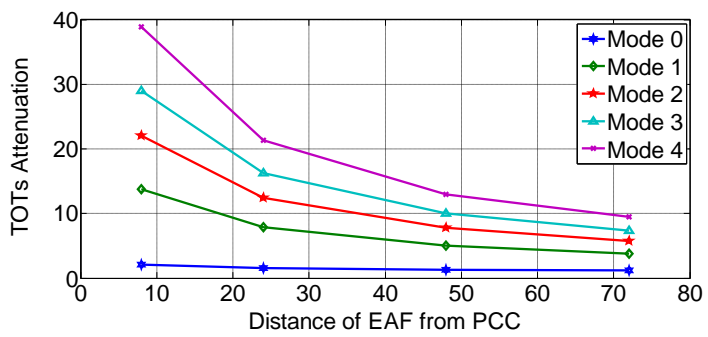

Fig. 17. Torque ratio (resonant to non-resonant condition) due to different distances between PCC and EAF

The amplified torsional torques at different modes at different distances between EAF and PCC are compared in Table XI. From Table XI, it is seen that as the distance between EAF and PCC is increasing, the TOTs are decreasing.

Fig. 17 shows the trend of decreasing torsional torques of different modes. It is seen that the rates of decrease of torque ratio are different for different modes. The higher modes of oscillation decreases at a higher rate upto $48 \mathrm{~km}$ distance then the decreasing rates become almost similar for the modes 1 to 4 . There is very insignificant change in torsional torque ratio of system mode (mode 0 ) which also proves that system mode is almost undisturbed by the frequencies produced in the electrical network.

From the analysis, it is assessed that greater the distance between generator and EAF, lesser the impact of EAF operation on the T-G shaft. Placing EAF at larger distance from generator do not eliminate the impact but it may be less harmful for the fatigue life of the T-G shaft. It requires metallurgical test of the shaft whether the existing amplified torsional torques are harmful for it or not.

\section{Conclusion}

To accomplish the assessment of impacts of multiple EAF operation at same PCC, the shaft system was designed by a simple lumped-mass model. The three-phase EAFs were modeled using MATLAB/Simulink from mathematical model of electric arc, where the resistances of the EAFs were varied deterministically in the frquency range of 1.2-45.5 Hz to meet the actual characteristics of EAF.

In the simulation, upto five EAFs were connected at the same PCC and its effect on T-G shaft was observed with/without resonant excitation of torsional modes. From investigation of simulation, it has been found that higher the mode are excited due to resonance larger the amplification of TOTs result. Also multiple number of EAFs at same PCC increases the amplification of TOTs. We consider all the EAFs are $8 \mathrm{~km}$ away 
from the PCC.The location of a single EAF was varied to investigate its impact on

T-G shaft. From the observation, it has been found that greater the distance between EAF and PCC, lesser its impact. The magnitude of torsoinal torques decreased non-linearly with increasing distance from PCC to EAF.

\section{Scope of Future Work}

In this work, amplification of TOT due to multiple EAF operation at same PCC and impact of locational changes of EAF has been investigated. From this investigations, $f$ ollowing few points can be assessed in future works:

(a) During torsional excitation, energy is absorbed by the oscillations/vibrations. Calculation of this amount of energy and investigation of its source should be studied.

(b) Subsynchronous resonance may also affect other rotating equipment which should be considered for further investigation.

(c) Only deterministic model of EAF was considered; stochastic model of EAF should be studied for comparison.

\section{References}

[1]. Song-Manguelle J., Sihler C., Schramm S., “ A General Approach of Damping Torsional Resonance Modes in Multi-megawatt Applications", IEEE Transaction on Industry Application, Vol. 47, No. 3, pp. 1390-1399, May-June 2011.

[2]. Lambrecht D. and Kulig T., "Torsional performance of turbine generator shafts especially under resonant excitation", IEEE Transactions on Power Apparatus and Systems, Vol. PAS-101, No. 10, October 1982

[3]. Smith K.S., Ran L., " Torsional Resonance Risk Management in Islanded Industrial Power Systems Supplying Large VFDs", Industry Applications Conference, 42 nd IAS Annual Meeting. Conference Record of the 2007 IEEE, pp. 2429-2438, 23-27 September 2007

[4]. Meckel C., "Mechanical damage of a subsynchronous cascade drive due to torsional resonance", Cement Industry Technical Conference, IEEE-IAS/PCA , pp. 133-150, 29 Apr 2001-03 May 2001

[5]. Ta-Peng Tsao, Jong-Ian Tsai, " Torsional interactions between an electrical arc furnace load and a turbine-generator set", Proceedings of the 2004 IEEE International Conference on Electric Utility Deregulation, Restructuring and Power Technologies (DRPT), Vol. 2, pp. 627-632, 2004

[6]. Jong-Ian Tsai, Chi-Hshiung Lin, Ta-Peng Tsao, “Assessment of long-term life expenditure for steam turbine shafts due to non-characteristic subharmonic currents in asynchronous links", IEEE Transactions on Power Systems, Vol. 19, No. 1, Pp. 507 - 516, 2004

[7]. Lin, W.M., Tsai, C.C., Lin, C.H., Tsao, T.P., "Alleviating shaft torsional vibrations caused by electric arc furnaces for a low capacity turbine generator by using a flywheel coupler", IEEE International Conference on Industrial Engineering and Engineering Management (IEEM), pp. 1771-1775, 2010

[8]. Solanics, P., Kozminski, K., Bajpai, M., Esztergalyos, J., Fennell, E., Gardell, J., Mozina, C., Patel, S., Pierce, A., Skendzic, V., Waudby, P., and Williams, J., "The Impact of Large Steel Mill Loads on Power Generating Units", IEEE Transactions on Power Delivery, Vol. 15, No. 1, pp. 24-30, January 2000

[9]. Ramey, D.G., Sismour, A.C., Kung, G.C., "Important Parameters in Considering Transient Torques on Turbine-Generator Shaft Systems", IEEE Transactions on Power Apparatus and Systems, Vol. PAS-99, Issue: 1, pp. 311-317, 1980

[10]. Tongxin Zheng, Makram, E. B., “An Adaptive Arc Furnace Model ”, IEEE Transactions on Power Delivery, Vol. 15, No. 3, pp. 931-939, July 2000

[11]. Robert, A., Janssens, N., Couvreur, M., Ledoux, P., Boon, G., Demaret, H., Nedden, L. Z., Deuse, J., Dubois, J., "Electromechanical Oscillations and Torsional Stresses of Generating Units near Arc Furnaces", cigre, http://www. cigre.org, 1998

[12]. Baker, D.H., Boukarim, G.E., D"Aquila, R., Piwko, R.J., 'SUbsynchronous resonance studies and mitigation methods for series capacitor applications", IEEE Power Engineering Society Inaugural Conference and Exposition in Africa, pp. 386 - 392, 2005

[13]. Kumar, R., Harada, A., Merkle, M., Miri, A.M., 'Investigation of the influence of series compensation in $\mathrm{AC}$ transmission systems on bus connected parallel generating units with respect to subsynchronous resonance (SSR)', Power Tech Conference Proceedings, IEEE Bologna, Vol. 3 , 2003

[14]. Kundur, P., Power System Stability and Control. New York: McGraw-Hill, 1994

[15]. Vervenne, I., Van Reusel, K., Belmans, R., "Electric Arc Furnace Modelling from a "Power Quality" Point of View", 3rd IEEE Benelux Young Researchers Symposium in Electrical Power Engineering Ghent, Belgium, April 2006

[16]. Mayordomo J.G., Beites L.F., Asensi R., Izzaddine M., Zabala L. and Amantegui J., “ A new frequency domain arc furnace model for iterative harmonic analysis," IEEE Transactions on Power Delivery, Vol. 12, pp. 1771-1778, October 1997 
[17]. Varadan, S., Makram, E. B., and Girgis, A. A., "A New Time Domain Voltage Source Model for an Arc Furnace Using EMTP,” IEEE Transactions on Power Delivery, vol. 11, no. 3, pp. 1685-1690, July 1996

[18]. Collantes-Bellido, R., Gomez, T., "Identification and Modelling of a Three Phase Arc Furnace for Voltage Disturbace Simulation”, IEEE Transactions on Power Delivery, Vol. 12, No. 4, pp. 1812-1817, October 1997

[19]. Carpinelli G., Iacovone F., Russo A. and Varilone P., “Chaos-bsed modelling of DC arc furnaces for power quality issues,' in IEEE Transactions on Power Delivery, Vol. 19, No. 4, pp.1869-1876, October 2004

[20]. Acha, E., Semlyen, A., Rajakovic, N., “A Harmonic Domain Computational Package for Nonlinear Problems and its application to electric Arcs', IEEE Transactions on Power Delivery, Vol. 5, No. 3, pp. 1390-1397, July 1990

[21]. Md. Minarul Islam, A. Hasib Chowdhury, "Aberrant Amplification of Torsional Oscillating Torques in Turbine-Generator Shaft Due to Multiple EAF Operation", ICECE/IEEE, pp. 631-634, 20-22 Dec. 2014. 